\title{
America's Public Bible
}

\section{Lincoln Mullen. America's Public Bible: Biblical Quotations in U.S. Newspapers. 2016. http://americaspublicbible.org/. Accessed January 17, 2018.}

Recent works of science fiction have explored the onset of artificial intelligence (AI) in society. Humans, West World, and Ex Machina explore the relationship between human and AI; experts in the field delight over the possibilities while warning of the potential perils of Artificial Superintelligence. Yet few address what happens when computers begin to read the Bible. America's Public Bible is one example of humans and machines uniting to benefit scholars of American religious history. The tool is a digital humanities project by Lincoln Mullen (currently an associate professor in the Department of History and Art History at George Mason University). The project won first prize in the Chronicling America Data Challenge and is due for a major upgrade in the fall thanks to a contract with Stanford University Press. ${ }^{1}$

America's Public Bible identifies biblical quotations and allusions found in newspapers from the mid-1800s through the 1920s derived from the Library of Congress project Chronicling America: Historic American Newspapers. Mullen's use of machine learning allows for the discovery of both direct citations of biblical texts (currently from only the King James Version) and allusions to biblical texts — such as this joke found in a 1899 Mississippi paper: "It is said that up in the moonshine district in east Tennessee a popular minister has this inscription posted on his door: 'Jug not lest ye be Jugged."' 2 The strength of the site's ability to identify such allusions allows the user to uncover verses that had entered the common vernacular of a community and as such had no need for citation.

The site allows users to explore 1,700 of the most frequently quoted verses in over twelve million newspaper articles. The site's most powerful feature is its search tool, which allows users to search for select verses, then sort the results by newspaper title, location, and date. The results list also includes a link to the newspaper page digitally archived by Chronicling America. ${ }^{3}$ The search results are also displayed in graph form (number of quotations per $100 \mathrm{M}$ words by date) to form a visual display of the passage's usage over time. Through the use of this powerful tool, historians can uncover patterns of usage corresponding to significant events and movements, and gain access to a comprehensive list of citations and illusions that can be viewed on the Chronicling America site.

America's Public Bible also offers a list of the most quoted verses by decade and a diagram of Bible chapters most frequently quoted together. However, both of these resources are static, and as such provide little aid to the scholar who might want to dig a bit deeper into the connections between the paired quotations, or explore further frequently quoted passages. Mullen does make this possible by allowing access to some of the project's raw data, but scholars would need significant expertise in digital humanities to put the data to use. In future iterations of the tool I would expect more robust functionality, allowing users to manipulate the data as they see fit. The updated and expanded version of this project which is due to be released in fall 2018 promises a greater number of biblical translations and the ability to search a broader array of biblical texts.

The current iteration of the site is well laid out and easy for users to navigate. The instructions for the search functionality are clear and concise, allowing users of all levels the ability to explore a variety of biblical texts with little need for outside instruction. However, those who will make the most use of America's Public Bible are those historians with the time to work through a number of citations and allusions to uncover trends in usage.

1 "NEH Announces the Winners of the Chronicling America Data Challenge," July 27, 2016, https://www.neh.gov/news/ press-release/2016-07-25.

${ }^{2}$ The Pascagoula Democrat-Star, November 10, 1899, 1.

${ }^{3}$ National Endowment for the Humanities, “Chronicling America: Historic American Newspapers,” https:// chroniclingamerica.loc.gov/. 
Furthermore, part of the prestige and depth of America's Public Bible derive from its use of the Chronicling America's digital archive. Unfortunately, this connection also proves a barrier to discovery, as the page load speeds for Chronicling America are inconsistent due to the large size of the digitized newspaper files that must be loaded on each page. For those without access to a high-speed Internet connection, the page load speed may hamper the tool's effectiveness. However, for those scholars with access to an Internet connection fast enough to load the bulky pages, America's Public Bible has the potential to expand the limits of research with the ability to search for biblical references in over twelve million newspaper pages from America's past.

Jacob DeBoer

Master of Divinity student

Candler School of Theology

Emory University 